\title{
"I see what I have been dreading": Witnessing Food and Violence in Waiting for the Barbarians and In the Heart of the Country
}

\author{
Nimisha Sinha, University of Hyderabad
}

This paper is a critical examination of the gazes that fall on food and on those who eat in J.M. Coetzee's In the Heart of the Country (1977) and Waiting for the Barbarians (1980). I refer to this phenomenon as 'food witnessing' and posit that they occur out of curiosity in 'the Other' or in attempt to consolidate or wield power. The paper argues that these gazes originate from violent impulses within a complex racial and gendered setting, and mimic a cannibalistic desire to consume the Other. It further explores questions about the body and senses that arise from watching someone eat, and complicates ideas of familiarity and distance between 'the Self' and 'the Other' as they occur in the novels.

\section{Introduction}

There is a common saying that one eats with the eyes first. This paper takes the saying literally as it tries to read the act of gazing as a kind of symbolic consumption through the respective protagonists of J.M. Coetzee's Waiting for the Barbarians (1980) and In the Heart of the Country (1977). Both novels are a first-person account of institutional violence and torture committed in historical and geographical obscurity and ambiguity. The narrative frame of both novels is set up through the reference of a protagonist who watches, observes, and tries to archive or convey their experiences through writing. With the advent of food photography in advertisements

and social media, food has become a sensuous object that first and foremost appeals to the gaze that holds the desire to ultimately own and consume the food item (Roland Barthes, Signe Rousseau, Carolyn Korsmeyer). In Coetzee, however, the food-related gaze falls on a person eating as a way to ultimately create distance from them, or to define "the Self" in opposition to them, or to absorb knowledge about "the Other". If we understand consumption as a form of assimilation and absorption, gazing becomes a kind of consumption too, where the goal is to conquer, absorb, and obliterate "the Other".

This paper examines the gaze of the respective narrators of the novels, the Magistrate and Magda, specifically through instances of looking at food, watching others eat, or using metaphors and images of consumption in the novels. Food is one of the more accessible modes of expression of violence in Coetzee. While forced hunger and starvation are common ways to inflict and read torture, this paper looks at violence inflicted in the presence of food. Food is a universally identifiable object and signifier that usually occupies the 'background' of a narrative in literature. For example, it is the central element of the Magistrate's relationship with the prisoners in Waiting for the Barbarians. Since he does not directly intervene to stop Colonel Joll's atrocities, food becomes a significant way in which he is able to extend his humanity and the hope in the Empire to the natives. Magda, on the other hand, lives a life of domestic servitude and her vocabulary, therefore, consists of food objects, family meals, and the contents of 
the kitchen. Food and its metaphors are essential to her narrative imagination. Food, then, becomes an easily available and manipulable signifier while depicting violence in both texts. This paper looks at the protagonists' relationship with food through the idea of 'food witnessing'.

'Food witnessing' refers to the symbolic violence that the witnessers commit on the objects of their gaze. The Magistrate and Magda are separated by their desires, power, and motivations and possess an uneasy relationship with authority. They watch people eat and describe it in their tales, both out of curiosity and as a way of gaining knowledge about "the Other." This paper will examine related issues of body, violence, and voyeurism by locating food within troubled colonial, racial, and gendered gazes. Jacques Derrida, in an interview with Jean-Luc Nancy, talks of the inevitability of consuming "the Other": "The so called nonanthropophagic cultures practice symbolic anthropophagy and even construct their most elevated socius, indeed the sublimity of their morality, their politics, and their right, on this anthropophagy" (114). The following section will shed light on how food is implicated by Coetzee very deliberately and very intricately into these numerous gazes, and that violence and metaphoric consumption are woven into it. Violence is an essential part of the act of food witnessing.

\section{Food Witnessing: Food and Consumption Related Gazes}

The agential choice to not look in Waiting for the Barbarians stands in stark contrast with the other abundant scenes of looking, watching, observing (and consequently, reading or interpreting) with wonder, discomfort, and disgust. In giving importance to the non-performance of an action, compelling us to critically examine the Magistrate's difficulty with looking at and recording torture: the Magistrate struggles to look at physical violence when Colonel Joll brings local people "roped together neck to neck" (29) and confines himself to his room to escape the sights and sounds of violence (31). While Joll deprives the prisoners of food, the Magistrate constantly tries to ensure their basic nourishment. In this indirect relationship with food, we can see the contradictions in the Empire and its many agents' relationship with the natives. It is a nonlinear, oppressive relationship that the Empire forces upon the natives. Feeding the Other, disrupting food chains, and legitimizing consumption become some of the ways in which this dynamic relationship is established.

Magda's story, by design, is not palatable or even believable: the false stories, the dream-like sequence of events, and frequent inconsistencies make her tales suspect. Through the long- winded stories of her lonely life, surrounded only by three other people, she lurks and spies, watching through windows, "through the chink in the curtain" (9), "by the light of the storm lantern I see..." (25). When she cannot look, she employs her imagination to paint a vivid picture of the going-ons in the house. Magda is possessed by an obsessive desire to look and observe, to know, and confront things that exclude her-and food is an essential item in this quest. She imagines a shift in power hierarchies through ideas of food service: "Soon I will be bringing my father and my maid breakfast in bed while Hendrick sounds in the kitchen eating biscuits" (49); and she comprehends her denial of family privileges through the 'noble' family meal: "I should have been invited too. I should be seated at that table" (52). Magda continuously uses vocabularies of food to imagine desires, materiality, and even to confirm her own bodily existence, "I think of tea and rusks and my saliva flows. There is no doubt about it, I am not pure spirit" (36). 


\section{The Possibility of Violence in Watching People Eat}

Watching other people eat can entice us, be an act of acquiring familiarity, and in Waiting for the Barbarians, it can even be an act of creating distance_of defining oneself against "the Other." In the earliest instances of looking at prisoners, the Magistrate notes their hunger, their fancy for 'civilized foods' like bread and tea, and most importantly, how they eat. He is aware of the innocence, helplessness, and hunger of the first set of prisoners. He asks the guards to give them food-using the Biblical word 'manna' for it-and writes:

The old man accepts the bread reverentially in both hands, sniffs it, breaks it, passes the lumps around. They stuff their mouths with this manna, chewing fast, not raising their eyes. A woman spits masticated bread into her palm and feeds her baby. I motion for more bread. We stand watching them eat as though they are strange animals. (26)

These descriptions of Others eating are impersonal and dehumanizing: those eating are Others to the witness. He cannot see their interiority-and so we get descriptions of external physiognomic and anatomical features like hands, mouths, and eyes. They do not seem to be eating like animals, but people look on as if they were. His account restricts description to the corporal-material.

The difference in Magda's descriptions of the "new wife" (1) and her dead mother in her first (false) story suggest that an eating body can be weaponized into a monstrous Other. In paragraphs numbered 2 and 4, we get a description of the "new wife," who she falsely claims her father has brought home, and of Magda's dead mother (2) respectively. Both of these are part of her imaginations; at this point in the narrative, it is impossible to verify any of these stories as true or false through our own reading:

2. The new wife. The new wife is a lazy big-boned voluptuous feline woman with a wide slow-smiling mouth. Her eyes are black and shrewd like two berries, like two shrewd berries. She is a big woman with fine wrists and long plump tapering fingers. She eats her food with relish. She sleeps and eats and lazes. She sticks out her red tongue and licks the sweet mutton-fat, from her lips. "Ah, I like that!" she says, and smiles and rolls her eyes. I watch her mouth, mesmerized. (1)

The imagery of a woman with berries for eyes could be read as an evocation of the non-human/ demonic or of a desirable, consumable object. Magda ascribes shrewdness to the berry-eyes. Most of the description is based upon watching her eat and enjoy flesh; the "new wife" is made into a gluttonous, villainous woman because she consumes and relishes food. Martha's imagined gaze falls directly on her eyes and mouth, and is fixated on this woman who eats - "I watch the full lips of this glutted woman" (4). The mother, on the other hand, is described as "a frail gentle loving woman" who, even as she was dying, was "patient, bloodless, apologetic" (2). Blood is an interesting symbol; while the new wife relishes a dead, now bloodless being, that is mutton, the mother is the bloodless being. The new wife is not only a replacement to her mother, but shall also devour Magda. Magda later tells us that there never was a new wife (16). She is the literal imagined Other.

29 | Sinha 
The narrative frames of both texts ensure that descriptions remain corporeal, even visceral. In both Magda and the Magistrate, we see the desire to comprehend the Other-to read and interpret them-before they reject the idea, and the desire is transformed into violence, as seen in the above analysis. Sheila Roberts argues that In the Heart of the Country looks like Magda's personal locked diary-one that she writes in to "rediscover her possible 'mothers" (23) as an ironic or temporary subversion of the Electra plot. Magda, writes Roberts, like most women and unlike the colonized, has no memory of "any utopian existence of living in equality side by side with men" (23), and so the images she uses typically come not from memory but fiction. Familiarity and distance play a fundamental role in how one imagines interpersonal relations with the Other, but is complicated by the consequences of the desire to watch the Other eat. It suggests an irreducible distance between the witnesser and the witnessed

\section{Distant Familiarity with the Eating Other}

Coetzee constructs a paternal, pitiful, and enquiring gaze in Waiting for the Barbarians that gradually turns destructive with increasing self-awareness. One could posit that the bodily familiarity it provides is what later fuels the desire to reinforce distance. This is most clearly seen in people's reactions to the prisoners: what starts with wonder and curiosity in the barbarians-the Others-eating civilized food finally ends in it becoming another nuisance: "For a few days the fisherfolk are a diversion with their strange gabbling, their vast appetites, their animal shamelessness, their volatile tempers. . . I stare down, invisible behind the glass. Then, all together, we lose sympathy with them. The filth, the smell, the noise of their quarrelling and coughing become too much" (28). The 'distant familiarity' of watching the Other eat sublimates into violent desires and brutal prejudices for the Magistrate, and the next section shows its transformation into the need to punish, erase, and obliterate the Other. The Magistrate's gaze is shrouded in the violent language of the Empire. In one scene, he partakes in gazing and staring at the prisoners along with a big group of people who watch the natives with lecherous intentions, perverted desires, or an idle curiosity. He "spend[s] hours watching them from the upstairs window (other idlers have to watch through the gate)" (27). He seems to always be watching them from his window above, even watching the other onlookers, and observing their food choices, appetites and other private rituals. Curiosity combines with surveillance as these displaced natives are displayed in the yard. A similar fixation on watching and trying to comprehend is repeated in his relationship with the Barbarian girl. He obsessively tries to decipher the marks on her body, trying to recreate and imagine the brute force on her feet, her eyes, and her sense of self.

In his many nights with her, he cleans and massages her feet and falls into a torpor, reflecting on his declining sexual desires and prowess. Despite living in proximity, she remains an Other that he simply cannot comprehend. The Magistrate writes, "But with this woman it as if there is no interior, only a surface across which I hunt... how natural a mistake to believe that you can burn or tear or hack your way into the secret of body of the other" (59). The desire to burn or tear or hack into her body to discover some secret is not very different from Joll's belief in some truth hidden to be forced out of the Barbarians.

Eating is largely considered to be a personal experience because it uses the relatively private senses of taste and smell, making it difficult to hold stable universal standards for it. In our contemporary world of food tourism and social media, the sense of sight has been implicated in a new form of

Sinha $\mid 30$ 
consumption via extravagant images of food and consumption. Watching someone eat is much like an inquisition into the Other's interiority and culture; following from Derrida, we can insist that the food-related gaze also assimilates and consumes the Other. However, in the texts before us, we see that food witnessing is ultimately a limiting exercise in knowing the Other. What one eats does not always tells us who they are:

Sundown after sundown, we have faced each other over the mutton, the potatoes, the pumpkin, dull food cooked by dull hands. Is it possible that we spoke? No, we could not have spoken, we must have fronted each other in silence and chewed our way through, time, our eyes, his black eyes and my black eyes inherited from him, roaming blank across their fields of vision. (3)

The word "fronted" is interesting. "We must have fronted each other" means that they have faced each other every day, and made themselves visible to each other. However, to put up a front also means to conceal the reality behind appearances. Food becomes a medium which transforms confrontation into a fronting: the possibility of action is substituted by chewing, which is an infinite repetition through time. The gaze 'roams blank' in the face of irreducible distance. The family meal is not a ritual of love or care; in In the Heart of the Country, the family meal is the performance of duty and subservience of brutal coexistence.

Magda's gaze is effectively piercing. She is able to find the truths about others through her own private surveillance efforts, or at least the truths that are good enough for her narrative. She keeps a watchful eye over everyone in the house, their routines and rituals, comings and goings. In describing her father's routine, she writes about his mealtime, "Before meals he washes his hands with soap. He drinks his brandy ceremonially, by himself, from a brandy-glass, of which he has four, by lamplight, sitting in an armchair" (31). This routine and its knowledge are important to her, because it is deviations in these everyday behaviors that alert her to his deviancy. She quickly catches digressions from these observances, for example, when he when he pushes his food away, asks her to leave during the meal, or makes his tea himself. She is able to confirm his "guilty thoughts" about Anna when he breaks his private ceremony, and "pecks his glass of brandy not sitting in his armchair but pacing about the yard in the moonlight" (33).

\section{Changing Expressions of Consumption}

In Waiting for the Barbarians, consumption is linked more closely with bodily reactions rather than sensory experiences. For example, the Magistrate watches the blind barbarian girl eat, and writes, "I watch her eat. She eats like a blind person, gazing into the distance, working by touch. She has a good appetite, the appetite of a robust young countrywoman" (41). Watching her eat becomes a feeble attempt to gain access into her interiority. Watching someone, especially watching someone eat, can be an act of familiarizing ourselves with them through the recreation of visceral reactions in our own bodies. In arguing for the aesthetics of food, scholars such as Kevin Sweeney, Carolyn Korsmeyer, and Emily Brady have noted the difference in treatment of the more objective and universal senses of sight, sound, and touch as opposed to the more personal senses of smell and taste. In Sweeney's "Can A Soup be

31 | Sinha 
Beautiful?" (2009), he argues that this is one of the reasons why food has been denied the category of the beautiful in eighteenth century aesthetic traditions. The focus of these arguments has generally been on the divide between the universal and personal senses in creating complex aesthetic experiences, but I wish to point to the use of sight and touch by Coetzee in describing consumption.

The first-person narrative of Waiting for the Barbarians implies that the Magistrate can write only about the sensory experiences that he can look at in others when they eat. Therefore, sight and touch are used almost exclusively to represent consumption of food. In a peculiar teasing of the senses, Coetzee complicates and contorts the familiar idea of consumption through the narrative framing of the text. Even when consumption is defined first-hand, the text shifts attention to the bodily reaction to food rather than the taste and smell of food. In In the Heart of the Country, there is a suggestion of a more complex notion of consumption that suggests an aesthetic of eating, "The sun is setting, the sky is a tumult of oranges and reds and violets. Up and down the stoep struts Klein-Anna mastering the shoes. If only we could eat our sunsets, I say, we would all be full" (85). The bright colors in the scenic image excites the eye, and consumption of beauty is compared to a metaphoric eating of a sunset.

\section{Gaze, Consumption and/of the Other: Obliterating the Other}

Finally, I want to talk about how the gaze, in both texts, exploits food to successfully obliterate the Other. The Magistrate, earlier, only "[passes his] his gaze over their surface absently, with reluctance" (34) but when the girl lives in close proximity with him, the surface of the barbarian body becomes reflective, "When she looks at me I am a blur, a voice, a smell, a centre of energy" (41). The blind barbarian girl cannot return his gaze. But when his own gaze reflects and falls back on him, it begins to diminish him. He begins to avoid the girl, and soon after, passes the girl when crossing over the kitchen:

Through wraiths of steam I see a stocky girl seated at a table preparing food. "I know who that is," I think to myself with surprise nevertheless, the image that persists in my memory as I cross the yard is of the pile of green marrows on the table in front of her. Deliberately I try to shift my mind's gaze from the marrows on the table in front of her. Deliberately I try to shift my mind's gaze from the marrows back to the hands that slice them, and from the hands to the face. I detect in myself a reluctance, a resistance. My regard remains dazedly fixed on the marrows, on the gleam of light on their wet skins. As if with a will of its own, it does not move. So I begin to face the truth of what I am trying to do: to obliterate the girl. (64)

The green marrows become a substitute for the girl, a way to shift gaze; this is a tacit acceptance of the fact that looking away is marked by brutality, not least the brutality of indifference. He does not wish to see the girl, because now his gaze falls back on him. The girl is stocky but when he looks at her, he only sees her hands or her face at a time, already fragmenting her body. The gleam of the skin of the marrows also strangely mirrors her skin, possibly gleaming from the wraiths of steam.

The series of events leading up to and following Magda shooting her father are intricately linked with items and vocabularies of the kitchen. She holds her gun "like a tray"; this innocuous metaphor forces a reconciliation of the image of a serving dish and of a weapon. She decides to kill her father after a 
dramatic night of violence and abuse, "[she] has had enough, tonight, of listening to the sounds that other people make" at the kitchen table and in their bedrooms. While shooting her father, she shuts her eyes to avoid not the sight of her patricide but "to keep me from seeing my father's nakedness" (63). She continues to describe him, his movements, his stupor in vivid detail as narrative time slows down. Standing over him, she describes the scene as follows:

125. The cups have not been washed.

126. There are flies in my father's room. The air is heavy with their buzzing. They crawl on his face and he does not brush them away, he who has always been a fastidious man. They cluster on his hands, which are red with blood. There are splashes of dried blood on the floor and the curtain is caked with blood. I am not squeamish about blood, I have made blood-sausage on occasion, but in this case I am not sure it would not be better to leave the room for a while, to take a stroll, to clear my head. However, I stay, I am held here. (65)

She stands over his dead body and describes in detail his room and body, and the surfaces where the blood has begun to dry. The image of blood returns, but this time she is responsible for it. She is surrounded, perhaps even covered in her father's blood, which she compares with blood sausages. Blood sausages are usually made from pork, dried pig's blood, and suet. While the odd and unsettling comparison between human and pig blood made through the example of food does not suggest a cannibalistic desire in Magda to literally consume him, but it points the reader towards a much more complex web of metaphoric relations of consumption in the novel.

\section{Conclusion}

Images of food or metaphors of consumption are strategically placed in the narratives to help express non-food related desires. The idea of consumption also includes the possibility of consuming the Other, thus, making the Other into a consumable object that can be conquered and absorbed. To consume also means to use up a resource. If Derrida says that consuming the Other is inevitable, this paper has tried to examine the processes and consequences of this kind of assimilation and appropriation of the Other. Shifting gazes between people and food, the subsequent conflation, and the borrowed language allows the protagonists to successfully consume the Other.

Food in literature has a dynamic presence. It is not limited by issues of survival or nourishment, and it does not serve the function of realistic embellishment alone. The meaning of food may differ for readers across the world, through space and time. It is impossible to fix a single allegorical meaning for food. In this paper, I have tried to demonstrate a food-related gaze in Coetzee that falls on an eating Other. The motivations for watching people eat are numerous: it is a curiosity in the Other, a way to create both bodily familiarity and distance, a way to distinguish ourselves from the Other, and a way to consolidate power. The racial/colonial/patriarchal gaze falls on the eating body to create Otherness and monstrosity, and Coetzee uses this to portray complex ideas of consumption. The violence of food witnessing vaguely mimics a cannibalistic desire to consume the Other: erase them, destroy them, or inflict brutalities on them. The impossibility of returning the gaze and the irreducible distance between the 33 | Sinha 
witnesser and the one being witnessed is testament to the imbalance in power between the two parties. Finally, I tried to show that the food-related gaze does not excuse itself, and gradually turns inwards to look back at itself in obsessive and futile attempts to confirm one's own materiality. 


\section{Works Cited}

Barthes, R., and A. Lavers. "Ornamental Cookery." Mythologies. Vintage, 1993.

Brady, Emily. "Smells, Tastes, and Everyday Aesthetics." The Philosophy of Food. University of California Press, 2012.

Cadava, E., P. Connor, and J.L. Nancy. "'Eating Well,' or the Calculation of the Subject: An Interview with Jacques Derrida." Who Comes After the Subject? Routledge, 1991, pp. 96-119.

Coetzee, John Maxwell. In the Heart of the Country. Penguin Books, 1977.

---. Waiting for the Barbarians. Penguin Books, 1999.

Korsmeyer, Carolyn. "Aesthetic Value, Art, and Food." Encyclopedia of Food and Agricultural Ethics, edited by Paul B. Thompson and David M. Kaplan. Springer Netherlands, 2013, pp. 1-8.

Monroe, Dave. "Can Food Be Art? The Problem of Consumption." Food and Philosophy: Eat, Think, and Be Merry. Wiley, 2009, pp. 133-144.

Roberts, Sheila. "Cinderella's Mothers: J. M. Coetzee's 'In the Heart of the Country.'" English in Africa, vol., 19, no. 1, 1992, pp. 21-33.

Rousseau, Signe. "Food 'Porn' in Media." Encyclopedia of Food and Agricultural Ethics, edited by Paul B. Thompson and David M. Kaplan. Springer Netherlands, 2013, pp. 1-8.

Sweeney, Kevin W. "Can a Soup Be Beautiful? The Rise of Gastronomy and the Aesthetics of Food." Food and Philosophy: Eat, Think, and Be Merry. Wiley, 2009, pp. 117-132.

Sweeney, K.W. The Aesthetics of Food: The Philosophical Debate About What We Eat and Drink. Rowman \& Littlefield, 2017.

---. "Can a Soup Be Beautiful? The Rise of Gastronomy and the Aesthetics of Food." Food and Philosophy: Eat, Think, and Be Merry, edited by F. Allhoff and D. Monroe, Wiley, 2009, pp. 11732, https://books.google.co.in/books?id=h49zM4fkO2kC. 